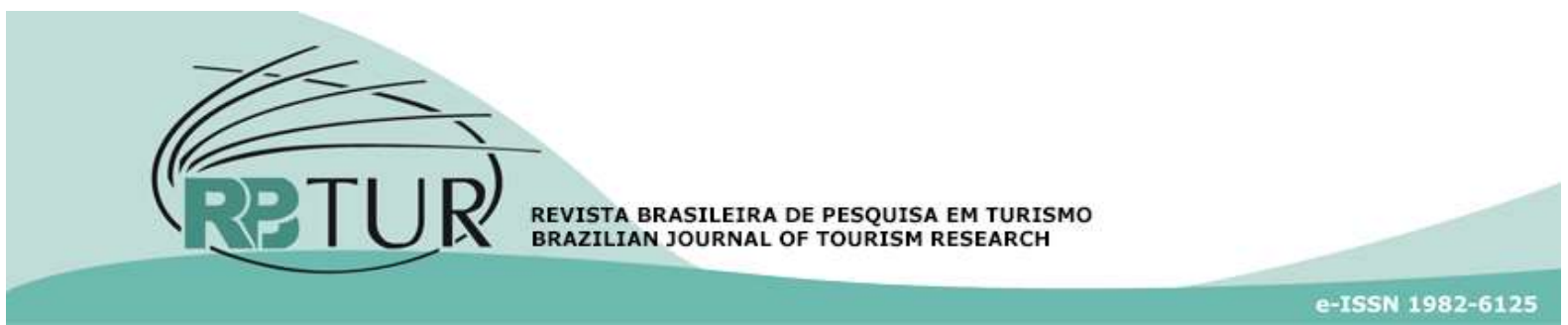

Artigo

DOI: $\underline{\text { http://dx.doi.org/10.7784/rbtur.v12i1.1372 }}$

\title{
Vamos almoçar? Um estudo da relação hospitalidade, qualidade em serviços e marketing de experiência na satisfação dos clientes de restaurantes
}

\author{
Let's have lunch? A study on the relation between hospitality, service \\ quality and experiential marketing in the satisfaction of restaurant \\ clients
}

\section{¿Vamos a comer? Un estudio sobre la relación entre la hospitalidad, la calidad del servicio y el marketing experiencial en la satisfacción de los clientes de los restaurantes}

\author{
Cláudio José Stefanini ${ }^{1}$ \\ Carlos Alberto Alves ${ }^{2}$ \\ Roseane Barcellos Marques ${ }^{3}$
}

Resumo: Propósito justificado do tema: O setor de bares e restaurantes da cidade de São Paulo é a região do país com a maior concentração de estabelecimentos, emprega cerca de 780.000 pessoas e o faturamento em 2015 foi superior a R\$30bi. A hospitalidade, a qualidade no serviço e a experiência no momento do consumo do produto estão intimamente ligados a satisfação e sua consequência fidelização, portanto inicialmente por estes aspectos o estudo se justifica. Objetivo: O objetivo deste estudo foi analisar o efeito da hospitalidade, qualidade em serviços e do marketing de experiência na percepção de satisfação entre os clientes de restaurantes frequentados para almoçar em horário comercial da cidade de São Paulo e a respectiva lealdade destes clientes. Metodologia/Design: A pesquisa é caracterizada como quantitativa descritiva, foi utilizado um questionário em escala Likert de sete pontos, para a coleta de dados utilizou-se a ferramenta formulários da plataforma Googledocs e o período de coleta dos dados foi nos meses de março e abril de 2017, a amostra foi não probabilística formada por 269 respondentes e a técnica multivariada de dados Modelagem de Equações Estruturais (SEM) para análise. Resultados: Verificou-se que a amostra foi predominantemente feminina, com idade superior a 30 anos que gasta entre $\mathrm{R} \$ 30,00$ e $\mathrm{R} \$ 50,00$ por dia e com alta escolaridade. Salienta-se que apesar dos resultados empíricos positivos da pesquisa estes não devem ser generalizados, pois sua amostra caracteriza um público específico da cidade de São Paulo. Originalidade: Este estudo adiciona novos insights a literatura

\footnotetext{
${ }^{1}$ Universidade Anhembi Morumbi (UAM), São Paulo, SP, Brasil. Elaboração do Referencial Teórico, Coleta dos Dados, Análise dos Dados, Relatório de Pesquisa e Revisão Final.

2 Universidade Anhembi Morumbi (UAM), São Paulo, SP, Brasil. Elaboração do Referencial Teórico, Coleta dos Dados, Análise dos Dados, Relatório de Pesquisa e Revisão Final.

${ }^{3}$ Universidade Anhembi Morumbi (UAM), São Paulo, SP, Brasil. Elaboração do Referencial Teórico, Relatório de Pesquisa e Revisão Final.
}

Artigo recebido em: 03/10/2017. Artigo aprovado em: 10/11/2017. 
sobre comportamento do consumidor especificamente nas áreas de hospitalidade e marketing de experiência em um setor representativo tanto por faturamento quanto por número de colaboradores da maior metrópole brasileira.

Palavras-chave: Comportamento do consumidor. Hospitalidade. Qualidade em serviços. Marketing de experiência. Restaurante.

\begin{abstract}
Justification of the topic: The city of São Paulo is the region of the country with the highest concentration of establishments in the sector of bars and restaurants, employing around 780,000 people, and the revenue in 2015 was greater than BRL\$ 30 billion. From the perspective of hospitality, service quality and the experience while consuming the product are intimately related to satisfaction and consequent loyalty. Therefore, this study is initially justified according to these aspects. Purpose: The objective of this study was to analyze the effect of hospitality, service quality and experiential marketing on the perception of satisfaction among clients in restaurants frequented at lunchtime during working hours in the city of São Paulo and the respective loyalty of these clients. Methodology/Design: This study is characterized as quantitative descriptive and used a questionnaire with a seven-point Likert scale. For the data collection, we used the forms tool on the Google Docs platform and the data collection period was in the months of March and April of 2017. We used non-probability sampling composed of 269 participants and the multivariate data analysis technique of Structural Equation Modeling (SEM). Findings: We observed that the sample was predominantly female, over 30 years of age, who spent between BRL\$ 30.00 and BRL\$ 50.00 per day and possess higher education. We would like to point out that despite the positive empirical results of the study, they should not be generalized, since this sample characterizes a specific group in the city of São Paulo. Originality: This study provides new insights for the literature on consumer behavior specifically in the areas of hospitality and experiential marketing in a sector represented as much by income as it is by the number of collaborators in the greater Brazilian metropolitan area.
\end{abstract}

Keywords: Consumer behavior. Hospitality. Service quality. Experiential marketing. Restaurants.

Resumen: Propósito justificado del tema: El sector de bares y restaurantes de la ciudad de São Paulo es la región del país con la mayor concentración de establecimientos, emplea cerca de 780.000 personas y la facturación en 2015 fue superior a R \$ 30bi. La hospitalidad, la calidad en el servicio y la experiencia en el momento del consumo del producto están íntimamente ligados a la satisfacción y su consecuente fidelización, por lo que inicialmente por estos aspectos el estudio se justifica. Objetivo: El objetivo de este estudio fue analizar el efecto de la hospitalidad, calidad en servicios y del marketing de experiencia en la percepción de satisfacción entre los clientes de restaurantes frecuentados para almorzar en horario comercial de la ciudad de São Paulo y la respectiva lealtad de estos clientes. Metodología/Design: La investigación se caracteriza como cuantitativa descriptiva, se utilizó un cuestionario en escala Likert de siete puntos, para la recolección de datos se utilizó la herramienta formularios de la plataforma Googledocs y el período de recolección de los datos fue en los meses de marzo y abril de 2017, la muestra no fue probabilística formada por 269 respondedores y la técnica multivariada de datos Modelado de Ecuaciones estructurales (SEM) para análisis. Resultados: Se verificó que la muestra fue predominantemente femenina, con edad superior a 30 años que gasta entre $R \$ 30,00$ y $R \$ 50,00$ por día y con alta escolaridad. Se destaca que a pesar de los resultados empíricos positivos de la investigación estos no deben ser generalizados, pues su muestra caracteriza a un público específico de la ciudad de São Paulo. Originalidad del documento: Este estudio añade nuevos insights a la literatura sobre comportamiento del consumidor específicamente en las áreas de hospitalidad y marketing de experiencia en un sector representativo tanto por facturación como por número de colaboradores de la mayor metrópoli brasileña.

Palabras clave: Comportamiento del consumidor. Hospitalidad. Calidad en servicios. Marketing de experiencia. Restaurante. 


\section{INTRODUÇÃO}

O objetivo deste estudo é analisar o efeito da hospitalidade, qualidade em serviços e do marketing de experiência na percepção de satisfação entre os clientes de restaurantes frequentados para almoçar em horário comercial da cidade de São Paulo e a respectiva lealdade destes clientes.

O ser humano tem uma relação distinta com o ato de se alimentar, essa característica está presente tanto na vida pessoal quanto na profissional, a comensalidade, ou seja, a ação de partilhar alimentos, bebidas ou ainda o estabelecimento de relações sociais, sentimentos e o fortalecimento de simbolismos (Carvalho, Bastos, \& GimenesMinasse, 2016), ainda reforçado por Krause \& Bahls (2016) salientando que a avaliação do consumidor não se restringe a somente estes aspectos e este artigo aborda os aspectos relativos às percepções dos clientes de restaurantes frequentados para almoços nos dias de trabalho.

A busca pela satisfação dos consumidores é parte inerente à atividade de gestão de qualquer negócio e principalmente nas pequenas empresas, pois a figura do gestor se confunde com a do proprietário e sua presença nas atividades rotineiras da empresa e proximidade com o cliente (Hwang \& Ok, 2013; Teng \& Chang, 2013). Este trabalho pretende analisar estes aspectos especificamente em restaurantes utilizados para almoçar pelos consumidores da cidade de São Paulo nos dias da semana.

A escolha do local para o almoço durante a semana de trabalho envolve aspectos objetivos e outros subjetivos, o custo, tipo de cozinha, atendimento, distância, espaço físico dentre outros pode-se dizer que são fatores objetivos enquanto as percepções de conforto, confiança, segurança e as sensações de bem-estar seriam os aspectos subjetivos.

Sob essa ótica a hospitalidade, a qualidade no serviço e a experiência no momento do consumo do produto estão intimamente ligados a satisfação e sua consequência fidelização, portanto inicialmente por estes aspectos o estudo se justifica, e ainda vale ressaltar que o setor escolhido para análise merece destaque pela sua relevância e importância econômica.

O setor de bares e restaurantes da cidade de São Paulo é a região do país com a maior concentração de estabelecimentos, aproximadamente 60.000 unidades e mais de 50 tipos de cozinha, emprega cerca de 780.000 pessoas e o faturamento em 2015 foi superior a R\$ 30bi ("Abrasel São Paulo," 2017). Portanto, é um setor importante da economia brasileira e assim justificando a presente pesquisa.

O processo de pesquisa é dinâmico e cíclico, dessa forma o presente estudo não tem a pretensão de findar o tema, mas sim contribuir para o aprimoramento da discussão sobre os temas de hospitalidade, qualidade em serviços, marketing de experiência, satisfação e fidelização. Adicionando a literatura um estudo quantitativo envolvendo além dos temas tradicionais um assunto ainda pouco explorado que é o marketing de experiência. 


\section{REFERENCIAL TEÓRICO}

\subsection{Hospitalidade}

A hospitalidade é oriunda das relações humanas e interpessoais que ocorrem nos ambientes sociais públicos ou privados. Envolve uma troca entre alguém que recebe (anfitrião) e em contrapartida está o recebido (cliente, hóspede), onde aquele que recebe troca algo com o que é recebido, podendo ser bens tangíveis ou intangíveis.

Cabe ressaltar que hospitalidade também pode ser compreendida, enquanto ramo de atividade, como: "a oferta de alimentos e bebidas e, ocasionalmente, acomodação para pessoas que não são membros regulares da casa" (Telfer, 2004, p.54). Deste modo a hospitalidade, enquanto oferta de um serviço, é abordada em domínio comercial (restaurantes) e parte-se da premissa de que o gerenciamento dos serviços se preocupa com o bem-estar de seus clientes e que, portanto, a hospitalidade deve contribuir para melhor atender às suas expectativas.

Nesta pesquisa, a noção de hospitalidade envolve a relação humana representada pelo anfitrião (colaborador, gestor) e pelo cliente. Uma vez que a hospitalidade se refere aos relacionamentos entre os seres humanos, destaca-se que uma empresa não é hospitaleira em si, mas seus colaboradores podem ou não ser hospitaleiros, principalmente aqueles que travam o contato direto com o cliente.

Camargo (2015) esclarece que: "Todas as culturas guardam princípios, leis não escritas da hospitalidade, herdadas de formas ancestrais de direito, não escritas, que regem o relacionamento humano em casa ou fora de casa" (Camargo, 2015, p. 47). Ao enfatizar o aspecto comercial da hospitalidade, considerando as questões epistemológicas, Telfer (2004, p. 63) aborda que: "se um hospedeiro comercial atende bem aos seus hóspedes, com um interesse autêntico por sua felicidade, cobrando um preço razoável não extorsivo por aquilo que oferece, suas atividades poderão ser chamadas de hospitaleiras". Por analogia, aplica-se a afirmação de Telfer (2004) ao anfitrião no restaurante, seja na pessoa do proprietário, gestor ou colaborador e que irá refletir na percepção do cliente.

No que concerne à motivação da hospitalidade em ambiente comercial encontrase a demanda, em razão de ser o cliente quem decide sobre o que consumir, isto é, o que vai comer ou beber. "Isso lhe dá um maior grau de opções e de controle sobre a experiência da hospitalidade, a que o provedor de hospitalidade comercial deve estar apto a responder" (Lockwood \& Jones, 2004, p.228).

Enquanto o cenário social é o principal foco da hospitalidade social, no comercial, o foco está na natureza da experiência de serviço pelo qual se paga, e que, portanto, poderá ser reclamada se desagradar ao cliente. Já dificilmente ocorre no social, pois raramente um convidado se queixa para o anfitrião social. Isto pode ser aclarado tendo em vista que no "ambiente comercial, a hospitalidade está sendo oferecida a um preço que proporcione ao menos sustentabilidade financeira e, talvez, lucro, e que valorize o cliente, enquanto no ambiente social a motivação do lucro e o dinheiro não estão em ques- 
tão" (Lockwood \& Jones, 2004, p.229).

As atitudes hospitaleiras e o espaço criado, no domínio comercial, representam a marca e os traços de personalidade do anfitrião Camargo (2015). Sendo assim, pode-se dizer que as atitudes hospitaleiras impactam positiva ou negativamente o serviço. $O$ estudo da hospitalidade vem ganhando maior evidência devido à busca por mais profissionalismo na oferta dos serviços. O desempenho dos colaboradores deve adicionar valor às empresas colaborando na diferenciação de produtos e/ou serviços processados. (Wada \& Camargo, 2006; Warech \& Tracey, 2004)

A provisão da hospitalidade em domínio comercial tem seu interesse na "organização, dinâmica e administração do encontro/experiência da hospitalidade, e como aperfeiçoa-la de diversos modos" (Brotherton \& Wood, 2004, p.201). Neste sentido pretende-se encontrar os efeitos da manifestação de hospitalidade na entrega dos serviços ofertados nos ambientes pesquisados, na ótica e percepção do consumidor.

Os aspectos de hospitalidade em restaurantes foram analisados por McPhail, Patiar, Herington, Creed, \& Davidson (2015) sob a ótica do colaborador. Esta pesquisa não exclui a importância da análise por esta ótica, contudo adiciona a ótica do cliente usando a escala desenvolvida por Blain \& Lashley (2014).

Ainda sob esta ótica Camargo (2004) afirma que o maior agregador de valor pode estar no 'como se faz', que faz toda a diferença na entrega do serviço nos domínios da hospitalidade (doméstica, pública e comer- cial). Isto porque a hospitalidade pode ser definida "como o ato humano exercido em contexto doméstico, público e profissional, de recepcionar, hospedar, alimentar e entreter pessoas temporariamente deslocadas de seu hábitat natural" (Camargo, 2004, p.52).

Serviços relacionados com hospitalidade deveriam, idealmente, refletir o prazer de conhecer novos clientes e cumprimentar antigos que estão de volta. "[...] Cortesia e consideração pelas necessidades dos clientes precisam ser aplicadas tanto a encontros pessoais como a interações por telefone" (Lovelock \& Wirtz, 2006, p. 88).

No estudo de Teng \& Chang (2013) a hospitalidade foi utilizada como variável mediadora quanto ao valor percebido pelos clientes de restaurantes em relação aos produz tos e serviços e, assim como abordado no estudo de Grönroos (1984) ao analisar restaurantes indicando que o cliente não está interessado somente no produto, pois ele quer analisar o processo em si.

A hospitalidade é manifestada plenamente em encontros interpessoais que possibilitam a criação de vínculos, no contexto comercial os aspectos hospitaleiros do anfitrião indicam a forma como o serviço é oferecido e a manifestação da percepção de valor por parte do cliente. Não o simples atender às necessidades, mas proporcionar uma experiência memorável. (Blain \& Lashley, 2014; Lovelock \& Wirtz, 2006; Lugosi, Lambie-Mumford, \& Tonner, 2014)

A partir do exposto pode-se afirmar que as características hospitaleiras proporcionam diferencial competitivo, portanto o estudo e identificação de tais características contribuem para o desenvolvimento de es- 
tratégias visando o atendimento e superação das expectativas dos clientes. A escala de Blain \& Lashley (2014) que compreende três construtos (Cliente primeiro, Cliente feliz e Cliente especial) conforme apresentado no Quadro 1 foi utilizada neste estudo para aferir as características hospitaleiras nos restau- rantes utilizados para almoçar em horário comercial da cidade de São Paulo. A escala original de Blain \& Lashley (2014) foi adaptada somente sua semântica para se adequar ao objeto de estudo, sendo o conjunto dos construtos considerados uma escala.

Quadro 1 - Escala Hospitabilidade Blain \& Lashley (2014) *

\begin{tabular}{|l|l|l|}
\hline Construto & \multicolumn{1}{|c|}{ Código } & \multicolumn{1}{c|}{ Abordagem da variável } \\
\hline \multirow{4}{*}{$\begin{array}{l}\text { Cliente } \\
\text { Primeiro }\end{array}$} & HOSP_1CF & Garantir que os clientes tenham excelentes momentos \\
\cline { 2 - 3 } & HOSP_2CF & Vontade de fazer com que seu cliente seja bem acolhido. \\
\cline { 2 - 3 } & HOSP_3CF & Proporcionar tranquilidade aos clientes como o ponto mais importante. \\
\cline { 2 - 3 } & HOSP_4CF & Satisfação dos clientes primeiro \\
\hline \multirow{4}{*}{$\begin{array}{l}\text { Cliente Fe- } \\
\text { liz }\end{array}$} & HOSP_1CH & Uma satisfação genuína para em atender os clientes. \\
\cline { 2 - 3 } & HOSP_2CH & Assumir a responsabilidade pelo bem-estar dos clientes. \\
\cline { 2 - 3 } & HOSP_3CH & Clientes demonstram aprovação pela sua hospitalidade. \\
\cline { 2 - 3 } & HOSP_4CH & Fazer o que os clientes esperam. \\
\cline { 2 - 3 } & HOSP_5CH & Oportunidades para ajudar os seus clientes. \\
\hline \multirow{4}{*}{$\begin{array}{l}\text { Cliente Es- } \\
\text { pecial }\end{array}$} & HOSP_1CE & Clientes se sintam únicos. \\
\cline { 2 - 3 } & HOSP_2CE & Estar na mesma sintonia que seus clientes. \\
\cline { 2 - 3 } & HOSP_3CE & Atenção dos funcionários a qualquer momento. \\
\cline { 2 - 3 } & HOSP_4CE & Sentem motivados ao assumir a responsabilidade pelo bem-estar. \\
\hline
\end{tabular}

* Escala original adaptada

A partir do exposto a primeira hipótese desta pesquisa é:

$\mathbf{H}_{1}$ : Os aspectos de hospitalidade percebidos pelos consumidores de restaurantes frequentados para almoçar em horário comercial da cidade de São Paulo influenciam a satisfação dos consumidores.

\subsection{Qualidade em serviços}

A percepção de qualidade em serviços envolve uma série de fatores que normalmente são medidos e avaliados, tais como: tangibilidade, confiabilidade, receptividade, segurança e empatia dos colaboradores (Guiry, Scott, \& Vequist, 2013). A evolução dos meios de comunicação trouxe uma atualização nas formas de avaliação e de percepção de qualidade entre os consumidores, portanto websites, blogs, aplicativos, redes sociais estão cada dia mais presente na relação de avaliação entre clientes e os fornecedores de serviços. (Aureliano-Silva, Oliveira, \& Alves, 2017; Lee, Chiang, \& Chen, 2012)

Especificamente em relação aos serviços prestados pelos restaurantes há características específicas, tais como: consumo imediato, capacidade do cliente de fazer comparações, além das demais características inerentes a prestação do serviço - qualidade do produto, atendimento, ambiente e preço (Angnes, Moyano, \& Lengler, 2015; Ryu \& Lee, 2017). O estudo de valores percebidos e 
satisfação dos colaboradores que assim promoveria elevado padrão qualidade na prestação de serviços e o cliente percebendo tal qualidade na prestação de serviços conforme os estudos de Dhar (2015a, 2015b).

Em seu estudo pioneiro Grönroos (1984) afirma que a qualidade percebida em relação aos restaurantes está ligada ao conjunto de características que ao final obtém o produto/serviço e não somente o produto ou serviço, ou seja, "o consumidor não está apenas interessado no que ele recebe como resultado do processo de produção, mas no próprio processo" (Grönroos, 1984, p. 36).

Tais características se sobressaem em relação ao que o restaurante entrega e elevam a expectativa dos clientes, portanto a percepção de qualidade estará afetada diretamente pelo ambiente, serviço prestado (colaboradores), preço, lealdade dos consumidores, qualidade da matéria prima, entre outras características extrínsecas ao produto. (Jung \& Yoon, 2013; Kim \& Jang, 2014; Stefanini, Souza, \& Yamashita, 2012; Teng \& Chang, 2013).

Para aferição deste construto optouse pela adaptação e aplicação da escala SERVQUAL desenvolvida por Parasuraman, Zeithaml, \& Berry (1988), conforme apresentado no Quadro 2, porém o construto tangibilidade foi excluído neste estudo, pois as variáveis tiveram peso inferior a 0,50 após o primeiro processamento da modelagem de equações estruturais pelo soft-

ware SmartPLS 3 conforme sugerido por Hair, Black, Babin, Anderson, \& Tatham (2010), este procedimento é detalhado no item 3 .

A semântica da escala original de Parasuraman et al. (1988) foi adaptada para se adequar ao objeto de estudo, sendo o conjunto dos construtos considerados uma escala.

Quadro 2 - Escala SERVQUAL Parasuraman et al. (1988) *

\begin{tabular}{|l|l|l|}
\hline Construto & Código & Abordagem da variável \\
\hline \multirow{5}{*}{ Tangibilidade*** } & SERVQ_Tang1 & Equipamentos com aparência moderna. \\
\cline { 2 - 3 } & SERVQ_Tang2 & Instalações físicas atraentes. \\
\cline { 2 - 3 } & SERVQ_Tang3 & Boa aparência dos funcionários. \\
\cline { 2 - 3 } & SERVQ_Tang4 & Qualidade dos catálogos, manuais e a sinalização do local. \\
\hline \multirow{5}{*}{ Confiança } & SERVQ_Conf5 & Manutenção dos serviços pelos prazos divulgados. \\
\cline { 2 - 3 } & SERVQ_Conf6 & Interesse em resolver os problemas dos clientes. \\
\cline { 2 - 3 } & SERVQ_Conf7 & Serviços combinados de maneira certa logo na primeira vez. \\
\cline { 2 - 3 } & SERVQ_Conf8 & Cumprimento dos prazos combinados. \\
\cline { 2 - 3 } & SERVQ_Conf9 & Registros comerciais e dos clientes sem erros. \\
\cline { 2 - 3 } & SERVQ_Conf16 & Funcionários cordiais com os clientes. \\
\hline \multirow{5}{*}{ Presteza } & SERVQ_Prest10 & Funcionários informam corretamente a execução dos serviços. \\
\cline { 2 - 3 } & SERVQ_Prest11 & Atende imediatamente os pedidos dos clientes. \\
\cline { 2 - 3 } & SERVQ_Prest12 & Funcionários dispostos a ajudar os clientes. \\
\cline { 2 - 3 } & SERVQ_Prest13 & Funcionários sempre livres para atender os pedidos. \\
\hline \multirow{5}{*}{ Segurança } & SERVQ_Seg14 & Funcionários com postura que inspira confiança aos clientes. \\
\cline { 2 - 3 } & SERVQ_Seg15 & Funcionários bem treinados para atender os clientes. \\
\cline { 2 - 3 } & SERVQ_Seg17 & Funcionários tem conhecimento para responder as dúvidas. \\
\hline
\end{tabular}

* Escala original adaptada.

*** Construto não aplicado neste estudo. 
A partir do exposto a segunda hipótese desta pesquisa é:

$\mathbf{H}_{2}$ : A qualidade percebida em relação ao restaurante frequentado para almoçar em horário comercial da cidade de São Paulo influencia a satisfação do cliente deste restaurante.

\subsection{Marketing de experiência}

$\mathrm{O}$ atendimento das necessidades dos clientes vem evoluindo e atualmente verifica-se que ao adquirir um produto o cliente espera algo mais, ou seja que o produto apesar de ser o objeto fim da negociação o processo de compra faz parte dos aspectos de satisfação, portanto a experiência de compra é um ponto de constante evolução e neste aspecto atua o enfoque do marketing de experiência. (Liu, 2016; Schmitt, 2010; Tynan \& McKechnie, 2009; Walls, 2013)

O estudo sobre o marketing de experiência de acordo com Tarţa (2013) iniciou-se com o conceito de "Economia de Experiência" de (Pine \& Gilmore, 1999) em que os autores definem como a satisfação gerada em uma experiência de compra em que os sentidos, envolvimento confortável, experiência personalizada e criação de valores únicos no processo de compra. (Liu, 2016; Pine \& Gilmore, 1999; Tarţa, 2013)

O marketing de experiência envolve diversos aspectos e não se limita a uma única dimensão, (Maghnati, Ling, \& Nasermoadeli, 2012) com base nos estudos desenvolvidos por Schmitt (1999) abordam cinco dimensões para caracterizar a experiência de compra, sendo: sentidos, emoções, sensações, ações e relevância conforme Quadro 3 (Liu, 2016; Maghnati et al., 2012; Schmitt, 1999, 2010; Tarţa, 2013). A semântica da escala original de Liu (2016) foi adaptada para se adequar ao objeto de estudo, sendo o conjunto dos construtos considerados uma escala.

Portanto, a satisfação do consumidor pode ser caracterizada por diversos fatores e os aspectos hedônicos também estão presentes, pois de acordo com Farias (2005), Farias \& Santos (2000) e Westbrook \& Oliver (1991) a emoção leva o consumidor a um outro estágio no momento da compra e sentimentos como prazer, alívio ou relaxamento, emoção e estes sentimentos se fundem no momento do consumo estimulando sentimentos externos a necessidade do produto ou serviço. Dessa forma os estímulos propostos pelo marketing de experiência são contextualizados e analisados neste trabalho. 
Quadro 3 - Escala de Marketing de Experiência*

\begin{tabular}{|c|c|l|}
\hline Construto & \multicolumn{1}{|c|}{ Código } & \multicolumn{1}{c|}{ Abordagem da variável } \\
\hline \multirow{4}{*}{ Sentido } & MKT-EXP_SENSE1 & Arquitetura e a decoração me remetem a um ambiente exótico. \\
\cline { 2 - 3 } & MKT-EXP_SENSE2 & Instalações criativas despertam emoções e boas lembranças. \\
\cline { 2 - 3 } & MKT-EXP_SENSE3 & Aprendo com propostas temáticas no restaurante. \\
\cline { 2 - 3 } & MKT-EXP_SENSE4 & Aprecio e me divirto com a arte presente no restaurante. \\
\cline { 2 - 4 } & MKT-EXP_SENSE5 & Acomodações confortáveis e confiáveis. \\
\cline { 2 - 3 } & MKT-EXP_SENSE6 & Eu me sinto relaxado, transportado no tempo e no ambiente. \\
\hline \multirow{4}{*}{ Emoção } & MKT-EXP_EMOT7** & Impressão é melhorada pelos serviços prestados funcionários. \\
\cline { 2 - 3 } & MKT-EXP_EMOT8 & Restaurante com espaços criativos e bem decorados. \\
\cline { 2 - 3 } & MKT-EXP_EMOT9 & Restaurante com uma atmosfera tranquila para comer. \\
\cline { 2 - 3 } & MKT-EXP_EMOT10 & Ambiente agradável e comida com boa aparência. \\
\cline { 2 - 3 } & MKT-EXP_EMOT11 & Restaurante espaçoso e confortável. \\
\hline \multirow{3}{*}{ Pensa- } & MKT-EXP_THINK12 & O ambiente e a arquitetura me surpreendem. \\
\cline { 2 - 3 } mento & MKT-EXP_THINK13 & Pratos temáticos permitem entender sobre a cultura de países. \\
\cline { 2 - 3 } & MKT-EXP_THINK14 & Festivais e eventos típicos para conhecer mais outras culturas. \\
\hline \multirow{4}{*}{ Ação*** } & MKT-EXP_ACTION15 & Oferta de festivais e eventos relativos a outras culturas. \\
\cline { 2 - 3 } & MKT-EXP_ACTION16 & Eventos de caráter ecológico atraem mais clientes. \\
\cline { 2 - 3 } & MKT-EXP_ACTION17 & Ações de marketing no restaurante são mais atrativos. \\
\hline
\end{tabular}

Fonte: Liu (2016)

* Escala original adaptada.

** Variável excluída do construto após primeiro cálculo da SEM, pois, apresentou carga inferior a 0,70 conforme sugerido por Hair, Ringle, \& Sarstedt (2011).

$* * *$ Construto não aplicado neste estudo.

A partir do exposto a terceira hipótese desta pesquisa é:

$\mathbf{H}_{3}$ : O marketing de experiência relacionado influencia positivamente a percepção dos consumidores de restaurantes frequentados para almoçar em horário comercial da cidade de São Paulo em relação à satisfação.

\subsection{Satisfação e Lealdade}

A literatura sobre percepção de qualidade em serviços é extensa e várias pesquisas convergem para a consequência de satisfação do cliente. Os aspectos de percepção de qualidade e até mesmo a intenção de recompra do produto em decorrência dessa satisfação normalmente estão presentes nestes estudos. (Namkung \& Jang, 2017; Shing,
Koh, \& Nathan, 2012; Werdini, Rejowski, \& Stefanini, 2014).

Considerando que clientes insatisfeitos procuram outro fornecedor do serviço, a identificação dos fatores que levam o cliente a aquisição do serviço e sua satisfação é fundamental para o sucesso das empresas, portanto a satisfação e a lealdade estão intimamente relacionadas e a lealdade uma consequência da satisfação. (Angnes et al., 2015; Johnson, Gustafsson, Andreassen, Lervik, \& Cha, 2001).

A lealdade dos clientes de restaurantes é dinâmica e apesar de diferenças culturais conforme apontadas por Kim, Lee, \& Mattila (2014), onde o cliente asiático não verbaliza sua opinião enquanto o ocidental assim o faz, porém, a lealdade está intimamente ligada à satisfação. 
Quadro 4 - Escala de Satisfação de Parasuraman et al. (1988)*

\begin{tabular}{|c|l|l|}
\hline Construto & \multicolumn{1}{|c|}{ Código } & \multicolumn{1}{c|}{ Abordagem da variável } \\
\hline \multirow{4}{*}{ Satisfação } & SERVQ_Emp18 & Satisfeito com a atenção individual aos clientes. \\
\cline { 2 - 3 } & SERVQ_Emp19** & Satisfeito com o horário de funcionamento (conveniente). \\
\cline { 2 - 3 } & SERVQ_Emp20 & Satisfeito com os funcionários (na quantidade e qualidade) \\
\cline { 2 - 3 } & SERVQ_Emp21 & Satisfeito pelo tratamento dos interesses do cliente com prioridade \\
\cline { 2 - 3 } & SERVQ_Emp22 & Satisfeito pelo atendimento das necessidades específicas. \\
\hline
\end{tabular}

* Escala original foi adaptada pelo autor.

** Variável excluída do construto após primeiro cálculo da SEM, pois, apresentou carga inferior a 0,70 conforme sugerido por Hair, Ringle, \& Sarstedt (2011).

Quadro 5 - Escala Lealdade de Srinivasan, Anderson, \& Ponnavolu (2002)*

\begin{tabular}{|c|c|l|}
\hline Construto & Código & \multicolumn{1}{c|}{ Abordagem da variável } \\
\hline \multirow{3}{*}{ Lealdade } & Leal1 & Continuarei comprando nesta loja. \\
\cline { 2 - 3 } & Leal2 & Recomendaria esta loja a parentes e amigos. \\
\cline { 2 - 3 } & Leal3 & Considero-me leal a esta loja. \\
\hline
\end{tabular}

* Escala original foi adaptada pelo autor.

A partir do exposto a quarta hipótese desta pesquisa é:

$\mathbf{H}_{4}$ : A percepção de satisfação em relação ao restaurante frequentado para almoçar em horário comercial da cidade de São Paulo influencia a lealdade do cliente deste restaurante.

A partir da apresentação e fundamentação dos construtos, escalas e hipóteses apresenta-se na Figura 1 o modelo de pesquisa a ser testado neste estudo.

\section{PROCEDIMENTOS METODOLÓGICOS}

No presente artigo pretendeu-se analisar a influência da hospitalidade e qualidade em serviços na satisfação do cliente de restaurante comercial da cidade de São Paulo e a respectiva lealdade do cliente ao restaurante que frequenta durante os dias da semana no horário do almoço.

A amostra foi do tipo não probabilística e por conveniência. Não probabilística, pois os questionários foram enviados aleatoriamente sem o uso de procedimentos estatísticos para seleção dos sujeitos e por acessibilidade, pois foram considerados os clientes que se dispuserem a responder a pesquisa. (Fávero, Belfiore, Silva, \& Chan, 2009)

Para a coleta de dados foi utilizada a plataforma GoogleDocs ${ }^{\circledR}$ por meio da ferramenta formulários, o período de coleta de dados foi entre os meses de março e abril de 2017 na cidade de São Paulo e região metropolitana. Os pesquisadores enviaram o link do questionário ao seu grupo de contatos e solicitado que posteriormente estes respondentes enviassem aos seus contatos, técnica conhecida como bola de neve. (Creswell, 2013)

A pergunta de corte para os respondentes foi se frequenta algum restaurante para almoçar durante a semana em seu horário de almoço. O questionário possuía 58 questões, sendo 7 perguntas descritivas para caracterizar a amostra e 51 afirmações em escala Likert de sete pontos (1) discordo to- 
talmente - (7) concordo totalmente, conforme apresentado nos quadros: Quadro 1, Quadro 2, Quadro 3, Quadro 4 e Quadro 5.

Para esta pesquisa foram adaptadas ao objeto do estudo três escalas já testadas e validadas originalmente, sendo: qualidade em serviços conhecida como SERVQUAL foram utilizados os constructos de tangibilidade e confiança de Parasuraman et al. (1988) Quadro 2, hospitalidade de Blain \& Lashley (2014) Quadro 1, satisfação por meio do constructo empregados da escala SERVQUAL de Parasuraman et al. (1988) Quadro 4 e o constructo lealdade de Srinivasan et al. (2002) Quadro 5. Para verificação do modelo proposto, após definir as escalas verificou-se o agrupamento das variáveis por meio da análise fatorial confirmatória.

A análise fatorial confirmatória ou análise do fator comum é uma técnica multivariada de interdependência que busca sintetizar as relações observadas entre um conjunto de variáveis inter-relacionadas, buscando identificar fatores comuns. A ideia básica reside na premissa de que é possível representar um conjunto de variáveis originais observadas por meio de um número menor de fatores intrínsecos. As variáveis das escalas foram testadas e os resultados confirmaram suas aderências aos fatores indicados como construtos. (Hair, Black, Babin, Anderson, \& Tatham, 2010)

Ao final do período de coleta de da- dos verificou-se que mais de 307 consumidores responderam à pesquisa, porém somente 269 questionários foram validados, pois alguns respondentes não frequentam regularmente restaurantes e por isso foram excluídos.

A pesquisa é definida como quantitativa descritiva, a amostra é não probabilística e por acessibilidade, a técnica multivariada de dados utilizada foi a modelagem de equações estruturais por meio do software SmartPLS 3 (Ringle, Wende, \& Becker, 2015). Para a análise dos dados, adotou-se a técnica de análise multivariada de dados Modelagem de Equações Estruturais (SEM, do inglês Structural Equation Modeling) de acordo com Hair et al. (2010, p.36) "[...] a modelagem de equações estruturais fornece a técnica de estimação apropriada e mais eficiente para uma série de equações de regressão múltipla separadas estimadas simultaneamente [...]".

Ainda segundo Hair et al. (2010, p.543) "a SEM é uma família de modelos estatísticos que buscam explicar as relações entre múltiplas variáveis". (Hair et al., 2010; Hair, Ringle, \& Sarstedt, 2011)

O modelo proposto com suas respectivas variáveis está disposto na Figura 1. São três construtos dependentes (Qualidade em serviços, Hospitalidade e Marketing de experiência) e a variável independente Satisfação, o modelo ainda inclui como consequência da satisfação - a Lealdade. 
Figura 1 - Modelo de pesquisa proposto

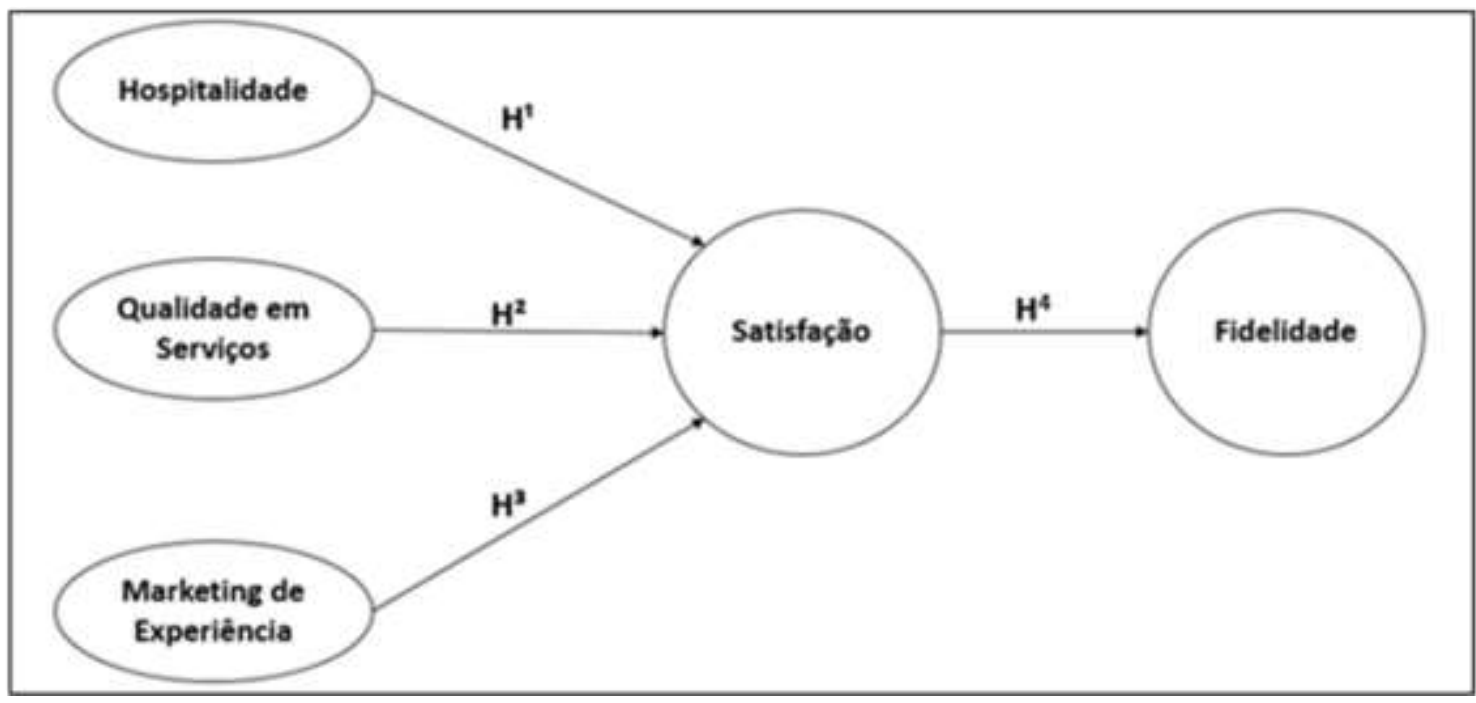

Fonte: Os autores (2017)

Neste estudo foi verificado o poder estatístico da amostra para analisar a probabilidade de a hipótese nula ser rejeitada, ou seja, quando esta hipótese é falsa (Cohen, 1977). A análise do poder estatístico envolve a relação entre quatro variáveis, sendo: tamanho da amostra (N), o critério de significância ( $\alpha)$, tamanho do efeito da população (ES) e o poder estatístico. (Erdfelder, Faul, \& Buchner, 1996; Faul, Erdfelder, Buchner, \& Lang, 2009)

A primeira análise denominada a priori é utilizada no planejamento da pesquisa e busca identificar o $\mathrm{N}$ em função das outras três variáveis ( $\alpha$, ES e poder estatístico). Utilizando o software G*Power3 este teste foi executado tomando por base os seguintes parâmetros: tamanho do efeito $=0,15$ considerado médio por Cohen (1977), valor de $\alpha=$ 0,05 , poder estatístico $=0,80$ e preditores $=14$ (marketing de experiência), considerando o construto com o maior número de variáveis (Hair et al., 2010). Conforme apresentado na Figura 2, o amostra mínima necessária neste estudo seria de 135 respondentes, portanto a pesquisa atende a este critério, pois, a amostra foi de 269 respondentes. 
Figura 2 - Teste do poder da amostra "a priori"

\begin{tabular}{|c|c|c|c|c|}
\hline Test family & \multicolumn{4}{|l|}{ Statistical test } \\
\hline F tests & \multicolumn{3}{|c|}{ Linear multiple regression: Fixed model, $\mathbf{R}^{x}$ deviation from zero } & 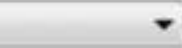 \\
\hline \multicolumn{5}{|c|}{ Type of power analysis } \\
\hline \multicolumn{4}{|c|}{ A priori: Compute required sample size - given $\alpha$, power, and effect size } & 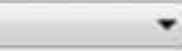 \\
\hline \multicolumn{3}{|l|}{ Input Parameters } & \multicolumn{2}{|l|}{ Output Parameters } \\
\hline \multirow[t]{6}{*}{ Determine $=>$} & \multirow{2}{*}{$\begin{array}{r}\text { Effect size } f^{1} \\
\alpha \text { err prob }\end{array}$} & 0.15 & \multirow{2}{*}{$\begin{array}{r}\text { Noncentrality parameter } \lambda \\
\text { Critical } F\end{array}$} & 20.2500000 \\
\hline & & 0.05 & & 1.7750306 \\
\hline & Power $(1-\beta$ err prob) & 0.80 & Numerator df & 14 \\
\hline & \multirow[t]{3}{*}{ Number of predictors } & 14 & Denominator of & 120 \\
\hline & & & Total sample size & 135 \\
\hline & & & Actual power & 0.8020044 \\
\hline
\end{tabular}

Fonte: Software G*Power (2017)

O teste post hoc para verificar o poder estatístico com base nos valores utilizados na pesquisa ( $E S=0,15$, valor de $\alpha=0,05$, $\mathrm{N}=269$ e preditores $=14$ ) alcançou o valor de
0,9942 ou seja, superando o valor convencionado $(0,80)$ conforme Figura 3. (Cohen, 1977; Erdfelder, Faul, \& Buchner, 1996; Hair et al., 2010).

Figura 3 - Teste do poder da amostra "post hoc"

\begin{tabular}{|c|c|c|c|c|}
\hline Test family & \multicolumn{4}{|l|}{ Statistical test } \\
\hline F tests & \multicolumn{3}{|c|}{ Linear multiple regression: Fixed model, $R^{2}$ deviation from zero } & - \\
\hline \multicolumn{5}{|c|}{ Type of power analysis } \\
\hline \multicolumn{4}{|c|}{ Fost hoc Compute achieved power - given $\alpha$, sample size, and effect size } & - \\
\hline \multicolumn{3}{|l|}{ Input Parameters } & \multicolumn{2}{|l|}{ Output Parameters } \\
\hline Determine $\Rightarrow$ & \multirow{2}{*}{$\begin{array}{l}\text { Effect size fo } \\
\alpha \text { err prob }\end{array}$} & 0.15 & \multirow{2}{*}{$\begin{array}{r}\text { Noncentrality parameter } \lambda \\
\text { Critical } F\end{array}$} & 40.3500000 \\
\hline & & 0.05 & & 1.7308784 \\
\hline \multirow{2}{*}{\multicolumn{2}{|c|}{$\begin{array}{l}\text { Total sample size } \\
\text { Number of predictors }\end{array}$}} & 269 & \multirow{3}{*}{$\begin{array}{r}\text { Numerator df } \\
\text { Denominator df } \\
\text { Power }(1-\beta \text { err prob) }\end{array}$} & 14 \\
\hline & & 14 & & 254 \\
\hline & & & & 0.9942532 \\
\hline
\end{tabular}

Fonte: Software G*Power (2017)

Portanto, o poder da amostra é considerado alto, vale salientar que previamente ao exame do poder estatístico a amostra foi submetida a uma análise em relação aos seus aspectos tais como: padrão de resposta, dados faltantes (missing), valores extremos (outliers) e distribuição. (Erdfelder et al., 1996; Faul et al., 2009)

Na próxima seção são apresentados os resultados obtidos a partir da pesquisa de campo e analisadas por meio do software SmartPLS 3 que de acordo com Ringle et al. (2015) tem objetivo de testar a validade do modelo proposto.

\section{APRESENTAÇÃO E ANÁLISE DOS RESULTADOS}

A partir dos dados da pesquisa de campo apresentados na Tabela 1 verifica-se que a amostra é predominantemente formada por mulheres $60,59 \%$, a escolaridade superior completa

$50,56 \%$ ou pós-graduação $43 \%$, a faixa etária de 31 a 50 anos $55,39 \%$ e $68,03 \%$ dos respondentes gasta em média de $\mathrm{R} \$ 20,01$ a $\mathrm{R} \$ 50,00$ para almoçar, portanto pode-se afirmar que nesta pesquisa o principal grupo respondente foi feminino, 
com escolaridade elevada, adulto e com gasto diário de até $\mathrm{R} \$ 50,00$. Verifica-se que o tipo de restaurante self service (por quilo) é predominante entre os respondentes da pesquisa $(72,86 \%)$.

Para elaboração da modelagem por equações estruturais inicialmente verifica-se a validade do modelo, neste estudo verificou- se a validade por meio do Alfa de Cronbach, Confiabilidade Composta e a Variância Média Extraída apresentados na Tabela 2, analisadas por meio do software SmartPLS 3 cujo objetivo é testar a validade do modelo proposto e explicados a seguir.

Tabela 1 - Estatística descritiva

\begin{tabular}{lrr} 
& Frequência & Percentual \\
\hline Escolaridade & & \\
Ensino Médio completo ou incompleto & 16 & $5,95 \%$ \\
Superior Completo ou incompleto/Cursando & 136 & $50,56 \%$ \\
Pós-graduação Completa ou Incompleta/Cursando & 117 & $43,49 \%$ \\
Valor médio de cada refeição & & \\
Até R\$ 20,00 & 80 & $29,74 \%$ \\
De R\$ 20,01 à R\$ 50,00 & 183 & $68,03 \%$ \\
De R\$ 50,01 à R\$ 80,00 & 5 & $1,86 \%$ \\
Acima de R\$ 80,01 & 1 & $0,37 \%$ \\
Sua faixa etária: & & \\
Até 30 anos & 88 & $32,71 \%$ \\
De 31 a 50 anos & 149 & $55,39 \%$ \\
Acima de 60 anos & 32 & $11,90 \%$ \\
Sexo & & \\
Feminino & 163 & $60,59 \%$ \\
Masculino & 106 & $39,41 \%$ \\
Tipo de Restaurante & & \\
Restaurante tradicional self service (por quilo) & 196 & $72,86 \%$ \\
Restaurante tipo preço único & 32 & $11,90 \%$ \\
Restaurante de rede fast food & 14 & $5,20 \%$ \\
Restaurante de rede (exceto fast food) & 10 & $3,72 \%$ \\
Restaurante da empresa & 5 & $1,86 \%$ \\
Restaurante vegetariano & 5 & $1,86 \%$ \\
Restaurante à la carte & $4,49 \%$ \\
Restaurante tipo churrascaria & 3 & $1,12 \%$ \\
\hline Fonte: Dados da pesquisa (2017) & & \\
\hline
\end{tabular}

Fonte: Dados da pesquisa (2017)

Tabela 2 - Indicadores de Confiabilidade e Validade dos Construtos

\begin{tabular}{lccc}
\hline Construto & Alfa de Cronbach & $\begin{array}{c}\text { Confiabilidade Com- } \\
\text { posta }\end{array}$ & $\begin{array}{c}\text { Variância Média Ex- } \\
\text { traída (AVE) }\end{array}$ \\
\hline Hospitalidade & 0,965 & 0,969 & 0,704 \\
Lealdade & 0,877 & 0,924 & 0,802 \\
Marketing de Experiência & 0,948 & 0,954 & 0,615 \\
Qualidade em Serviços & 0,946 & 0,952 & 0,539 \\
Satisfação & 0,876 & 0,916 & 0,731 \\
\hline
\end{tabular}

Fonte: Dados da pesquisa - SmartPLS (2017)

A Variância Média Extraída (AVE) de acordo com Hair et al. (2010, p. 589) é "uma medida de convergência em um conjunto de itens que representa um construto latente. É o percentual médio de variação explicada entre os itens", ainda de acordo com Hair et al. 
(2010) para sugerir validade convergente adequada a AVE deve ser maior ou igual a 0,50 , portanto todos os construtos apresentaram validade convergente adequada.

A Confiabilidade Composta é uma medida da confiabilidade geral de uma coleção de itens heterogêneos, mas semelhantes (Hair et al., 2010), os resultados desta medida estão acima de 0,70 (Tabela 2) que sugerem confiabilidade geral conforme (Hair et al., 2010).

De acordo com Hair et al. (2010, p. 100) "Alpha de Cronbach's é uma medida de confiabilidade que varia de 0 a 1 , sendo valores de 0,60 a 0,70 considerados o limite infe- rior de aceitabilidade". Para este estudo, adotou-se o critério de aceitação em relação ao Alpha de Cronbach's mínimo 0,70, conforme apresentados na Tabela 2 os valores de todos os construtos apresentaram aceitabilidade a partir deste critério.

A validade discriminante das variáveis latentes é comprovada, quando se verifica que as raízes quadradas de cada variável são superiores à correlação entre elas e as demais variáveis latentes dos modelos (Fornell \& Larcker, 1981), o modelo apresenta apenas uma variável que não atende o pressuposto, como demonstrado na Tabela 3.

Tabela 3 - Validade Discriminante do Modelo

\begin{tabular}{lccccc} 
Construtos & Hospitalidade & Lealdade & $\begin{array}{c}\text { Marketing de } \\
\text { Experiência }\end{array}$ & $\begin{array}{c}\text { Qualidade } \\
\text { em Serviços }\end{array}$ & Satisfação \\
\hline Hospitalidade & $\mathbf{0 , 8 3 9}$ & & & & \\
Lealdade & 0,635 & $\mathbf{0 , 8 9 5}$ & & & \\
Marketing de Experiên- & 0,555 & 0,466 & $\mathbf{0 , 7 8 4}$ & & \\
cia & 0,796 & 0,783 & 0,560 & $\mathbf{0 , 7 3 4}$ & $\mathbf{0 , 8 5 5}$ \\
Qualidade em Serviços & 0,829 & 0,684 & 0,578 & 0,873 & \\
Satisfação &
\end{tabular}

Fonte: Dados da pesquisa - SmartPLS (2017)

Como apenas uma variável dentro da validade discriminante não atendeu o pressuposto (Qualidade em Serviços) e os demais índices de ajustamento apresentam valores ótimos, decidiu-se pela continuidade da análise do modelo estrutural e o teste de hipóteses.

A partir da análise apresentada, podese afirmar que há validade e confiabilidade para o modelo proposto, pois estes apresentaram resultados superiores ao mínimo para sua aceitação. A Figura 4 apresenta o modelo final de satisfação em relação ao restaurante frequentado para almoçar durante a semana. Este modelo é responsável por $83,7 \%$ da per cepção da satisfação em relação ao restaurante e a satisfação responsável por $46,8 \%$ sobre a lealdade, valores considerados expressivos em pesquisas em ciências sociais de acordo com Oliveira, Silva, Rodrigues, \& Borges (2014). 
Figura 4 - Resultado Geral do Modelo

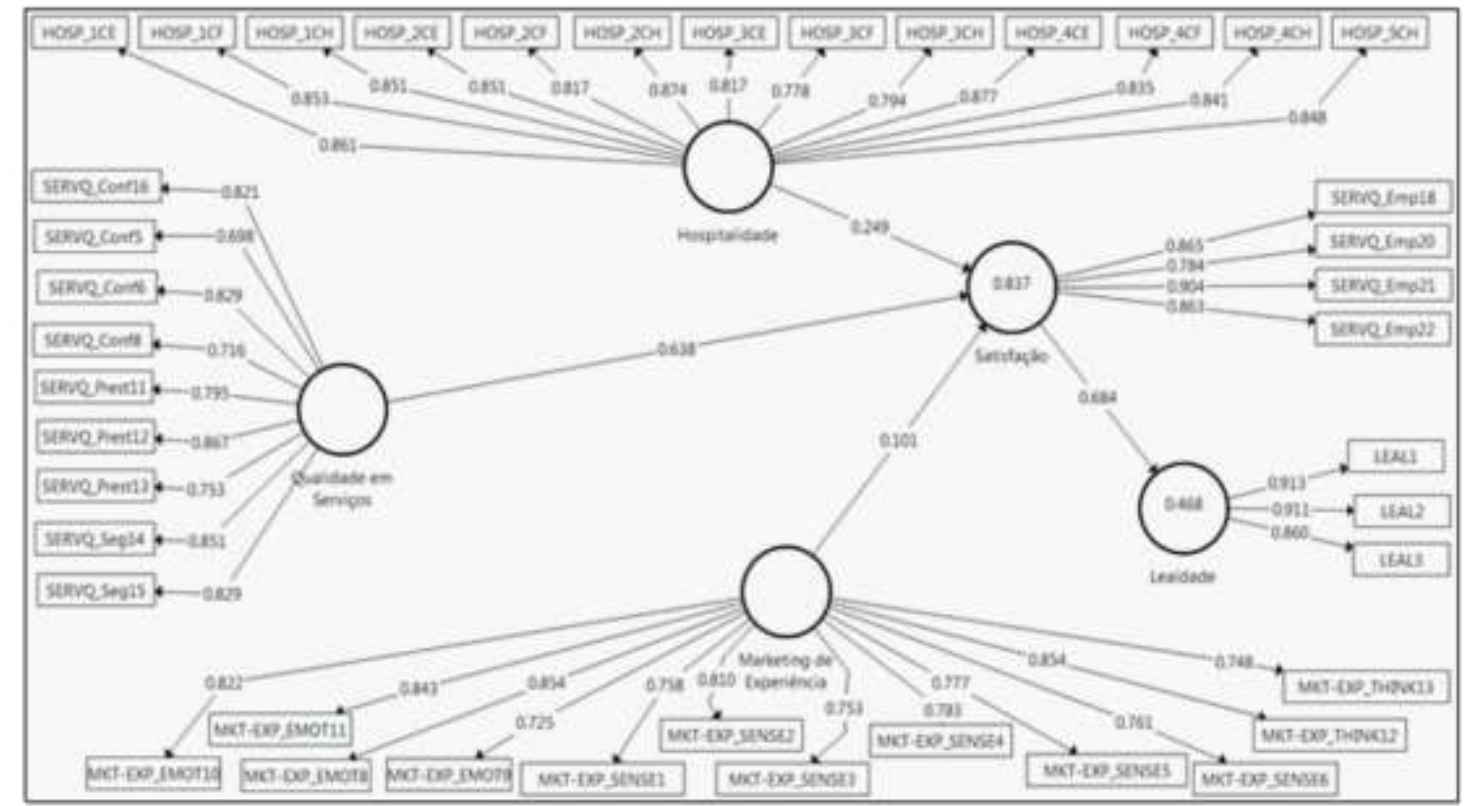

Fonte: SmartPLS 3 - Pesquisa de Campo (2017)

O modelo de pesquisa proposto neste estudo foi aplicado e analisado a Figura 4 apresenta os resultados da modelagem, por meio do qual é possível verificar que este modelo explica 83,7 \% dos fatores envolvidos na satisfação do consumidor deste cliente e 46,8\% da lealdade. $O$ efeito observado refere-se à analise desenvolvida por Arsham (1988) que classifica o efeito observado sobre a hipótese em evidência muito forte $(p \leq 0,01)$, evidência moderada $(0,01 \leq P<0,05)$, evidência sugestiva $(0,05 \leq P<0,10)$ e pouca ou nenhuma evidência real $(0,10 \leq P)$.

Tabela 4 - Avaliação do Modelo Estrutural Hipotético $\left(R^{2}=0,837\right)$

\begin{tabular}{|c|c|c|c|c|c|c|}
\hline $\begin{array}{l}\text { Hipó- } \\
\text { teses }\end{array}$ & Relação & $\boldsymbol{\beta}$ & $p$-values & $\begin{array}{c}\text { Efeito } \\
\text { Hipotético }\end{array}$ & $\begin{array}{c}\text { Efeito Ob- } \\
\text { servado }\end{array}$ & $\begin{array}{r}\text { Resultado } \\
\text { (Hipótese) }\end{array}$ \\
\hline $\mathrm{H}_{1}$ & Hospitalidade -> Satisfação & 0,249 & $0,000^{*}$ & Positivo & Forte & \\
\hline $\mathbf{H}_{2}$ & Qualidade em Serviços -> Satisfação & 0,638 & $0,000^{*}$ & Positivo & Forte & Suportada \\
\hline $\mathbf{H}_{3}$ & $\begin{array}{l}\text { Marketing de Experiência -> Satis- } \\
\text { fação }\end{array}$ & 0,101 & $0,0180 * *$ & Positivo & Moderado & Suportada \\
\hline $\mathrm{H}_{4}$ & Satisfação -> Lealdade & 0,684 & $0,000 *$ & Positivo & Forte & Suportada \\
\hline
\end{tabular}

Fonte: Dados da pesquisa - SmartPLS (2017)

Nota: ${ }^{*} p \leq 0,01, * * p \leq 0,05, R^{2}=0,837$

Os resultados ora apresentados apontam para suportar as hipóteses, porém é importante ir além dos números para explicar tais resultados conforme já citado anteriormente de acordo com Carvalho et al. (2016) a ação de partilhar, alimentos, bebidas ou ainda o estabelecimento de relações sociais, sentimentos e o fortalecimento de simbolismos, portanto os resultados ora apresentados podem representar aspectos que vão além da análise fria dos resultados. Inicialmente para analisar os aspectos propostos neste artigo, abordou-se quatro hipóteses as quais são analisadas a seguir. 
Há indícios que a hipótese $\mathrm{H}_{1}$ (a percepção que a hospitalidade nos restaurantes influencia a satisfação do cliente) é suportada de acordo com os resultados presentes neste estudo (Tabela 3), assim pode-se afirmar que este cliente associa a satisfação em relação ao serviço prestado e os aspectos de hospitalidade ratificando os estudos de Teng \& Chang (2013).

Os aspectos de hospitalidade verificados a partir da escala desenvolvida por Blain \& Lashley (2014) com os construtos de cliente feliz, cliente especial e cliente primeiro e aplicada neste estudo foram identificados e assim indicando que a hipótese 1 é suportada, estes aspectos confirmam os resultados encontrados em diversos estudos, tais como: o valor percebido pelos clientes também presente no estudo de Teng \& Chang (2013) ou na percepção de valor pelo produto entregue (Brotherton \& Wood, 2004) ou ainda pela afirmação de Telfer (2004) quando se refere ao valor cobrado ser justo pelo que é entregue.

Ainda no enfoque da hospitalidade pode-se afirmar que a partir do enfoque do colaborador há adição de valor no serviço prestado, seja por meio dos traços de personalidade do anfitrião (Camargo, 2015), da cortesia (Lovelock \& Wirtz, 2006) do desempenho do colaborador adicionando valor ao serviço prestado (Wada \& Camargo, 2006; Warech \& Tracey, 2004) ou ainda especificamente num estudo em restaurantes desenvolvido por McPhail et al. (2015) em que o colaborador tem papel fundamental na percepção de hospitalidade. Portanto, conforme apresentado, diversos estudos ratificam os resultados ora apresentados referente à hipótese 1 e assim justificando sua aceitação.

A segunda hipótese $\left(\mathrm{H}_{2}\right)$ abordou os aspectos de qualidade em serviços influenciando a satisfação dos clientes de restaurantes e há indícios que suportam esta hipótese, apesar de diversos estudos já abordarem esta relação é importante a aferição da escala em outros tipos de serviços, ambientes e consumidores, pois as escalas sofrem alteração em decorrência de tradução ou na adaptação ao objeto de estudo, reforça-se a ideia que pesquisas acadêmicas são um meio e não um fim, portanto deve haver uma evolução constante no pensamento.

Os resultados apresentados indicam que a hipótese pode ser suportada assim como em outros estudos que podem suportá-la. A escala utilizada foi a SERVQUAL (Parasuraman et al., 1988) e os construtos utilizados foram confiabilidade, presteza e segurança conforme já esclarecido anteriormente, nestas características pode-se afirmar que a hipótese é suportada ratificando os resultados dos estudos de Guiry et al. (2013) e Stefanini et al. (2012).

Em relação ao serviço prestado podese afirmar que os resultados ora encontrados corroboram os estudos de Dhar (2015a; 2015b) ou se além do serviço prestado incluise a qualidade intrínseca ao produto conforme analisado por Jung \& Yoon (2013), Kim \& Jang (2014) e Teng \& Chang (2013), as características inerentes ao atendimento estão presentes nos estudos de Aureliano-Silva et al. (2017) e Lee et al. (2012) assim como nos estudos de Angnes \& Moyano (2013) e Angnes et al. (2015) e finalmente o conjunto 
de características sendo o que aporta diferencial ao negócio foi pesquisado por Grönroos (1984). A partir do exposto pretendeu-se suportar a afirmação da hipótese 2 em que a qualidade em serviços teria efeito positivo sobre a satisfação do cliente de restaurantes.

A terceira hipótese $\left(\mathrm{H}_{3}\right)$ abordada diz respeito aos aspectos da experiência e a partir dos estudos de Schmitt (1999; 2010) que abordam a satisfação como consequência da evolução da experiência de compra, ou seja, o cliente mesmo que inconscientemente deseja algo além do produto ou serviço que está comprando (Liu, 2016; Schmitt, 1999, 2010; Tynan \& McKechnie, 2009; Walls, 2013). Esta hipótese foi confirmada conforme Tabela 3 ao nível de $5 \%$ de significância.

Pretendeu-se analisar os aspectos que vão além da aquisição de um produto ou serviço, ou seja a experiência de compra numa situação rotineira deste consumidor, utilizou-se a escala desenvolvida por Liu (2016) que contém os construtos de marketing de sensação, marketing de emoção, marketing de ação, marketing do pensamento e marketing dos aspectos relevantes, esta escala é uma evolução da escala desenvolvida inicialmente por Schmitt (1999; 2010).

Apesar do marketing de experiência ser um tema de estudo novo, principalmente no Brasil, verifica-se em diversos estudos sua relevância e atualidade, pois no enfoque da experiência de compra como já relatado nos estudos de Liu (2016), Schmitt (1999; 2010), Tynan \& McKechnie (2009) e Walls (2013) ou ainda a importância da economia da experiência conforme os estudos de Pine \& Gilmore (1999) e Tarţa (2013) reforçando e corrobo- rando o aceite da hipótese, pois o cliente está interessado nos produtos e serviços que vão além da compra e suas dimensões (Maghnati et al., 2012) tais como sentido, emoção, sensação ou ações. (Liu, 2016; Maghnati et al., 2012; Schmitt, 1999, 2010; Tynan \& McKechnie, 2009)

Finalmente a quarta hipótese $\left(\mathrm{H}_{4}\right)$ deste estudo analisou a influência da satisfação na fidelização do cliente de restaurantes frequentados em horário comercial da cidade de São Paulo. Esta hipótese foi confirmada conforme apresentado na Tabela 3, verifica-se uma variância total explicada de 0,837 ou seja, $83,7 \%$ da variável dependente consegue ser explicada pelos regressores presentes no modelo.

A satisfação gerando lealdade pode ser corroborada pelos estudos de Angnes et al. (2015) e Johnson et al. (2001), a fidelização aparentemente é uma consequência de satisfação, porém nem sempre o cliente repete tal comportamento, pois, outras variáveis como preço, prazo, expectativa do cliente entre outros fatores poderão influenciar o comportamento. Os aspectos hedônicos como os analisados pelo construto de marketing de experiência podem explicar esse comportamento de satisfação, mas não necessariamente fidelização do cliente. (Farias, 2005; Farias \& Santos, 2000; Westbrook \& Oliver, 1991)

A lealdade do consumidor envolve fatores que nem sempre é possível identificare captar por uma pesquisa quantitativa, o resultado ora apresentado demonstra bem tal observação, pois apesar de um $R^{2}$ de 0,837 para a satisfação verifica-se o valor de 0,468 para a fidelização (Tabela 3), portanto a satis- 
fação não necessariamente levará o consumidor a fidelização e a intenção de recompra demonstra o desejo do consumidor de repetir a compra e assim gerar sua fidelização. (Kim, Lee, \& Mattila, 2014; Namkung \& Jang, 2017; Shing, Koh, \& Nathan, 2012; Werdini, Rejowski, \& Stefanini, 2014)

$\mathrm{Na}$ análise das hipóteses apresentadas há indícios que são suportadas (Tabela 3), porém é necessário salientar que alguns aspectos não são visíveis pelos resultados quantitativos e merecem destaque. $\mathrm{O}$ primeiro ponto é o fato da pesquisa retratar uma situação rotineira entre os paulistanos, porém com uma relevância que dificilmente pode ser retratada sem destacar o rito da alimentação entre este público, pois até mesmo o momento do café é relevante, portanto a escolha do local, do tipo de comida e das companhias para o almoço possuem um peso muito alto e merece ser salientado neste estudo. Dessa forma é importante relatar a confirmação ou não das hipóteses assim como estas peculiaridades serem salientadas.

\section{CONSIDERAÇÕES FINAIS}

O objetivo deste estudo foi analisar o efeito da hospitalidade, qualidade em serviços e do marketing de experiência na percepção de satisfação entre os clientes de restaurantes frequentados para almoçar em horário comercial da cidade de São Paulo e a respectiva lealdade destes clientes. Para tanto, verificou-se por meio da modelagem de equações estruturais tal relação e assim a análise das hipóteses e consequentemente o atingimento do objetivo proposto.
A amostra deste estudo foi predominantemente do sexo feminino, com escolaridade em nível superior ou pós-graduação, com idade entre 30 e 50 anos, frequentadores de restaurante do tipo self service (por quilo) e o gasto médio de $R \$ 30,00$ a $R \$ 50,00$ por refeição conforme Tabela 1. Vale salientar que os resultados apresentados são específicos desta amostra sem a pretensão de se generalizar, porém não deixando de destacar sua relevância pela carência de estudos desta população.

Estudar aspectos relativos à percepção de qualidade em serviços e hospitalidade é relativamente comum nos estudos com foco no comportamento do consumidor, porém este trabalho adiciona aos estudos um tema novo e ainda pouco explorado - o marketing de experiência, além da incorporação de técnicas multivariadas e a adaptação de escalas validadas em outras áreas e em outro idioma para a pesquisa acadêmica nacional, facilitando a aplicação e adaptação pelos pesquisadores e estudantes locais sua utilização.

Conforme discutido no capítulo anterior há indícios para afirmar que as hipóteses foram confirmadas, pois os resultados apresentados na Tabela 3 reforçam sua aceitação, porém é importante destacar que os resultados quantitativos apesar de validar as hipóteses sempre devem ser vistos com cautela e sua generalização ser usada com parcimônia e os resultados obtidos representar um ponto de análise para viabilizar decisões gerenciais, estratégicas ou mesmo para a programação rotineira dos recursos. Outras análises que possam esclarecer ou mesmo trazer pontos de vista distintos devem ser incorpo- 
radas a esta análise para agregar valor, distinguir as peculiaridades ou mesmo propor alternativas para a tomada de decisão e assim melhorar a competitividade da empresa.

A presente pesquisa adiciona a literatura sobre comportamento do consumidor, especificamente nos aspectos relativos a hospitalidade um enfoque diferenciado além de trazer um tema emergente na literatura, pois o marketing de experiência apesar de pouco pesquisado, principalmente no Brasil está cada vez mais presente em estudos sobre comportamento do consumidor. Para pesquisas futuras pode-se aplicar a análise multigrupo em modelagem de equações estruturais (Multi-group Analisys - MGA), por meio do qual será possível identificar diferenças entre grupos, tais como homens e mulheres, faixa etária, classe social ou ainda outros tipos de agrupamento. A partir da pesquisa realizada e em relação aos aspectos gerenciais sugere-se especial atenção dos gestores para prover recursos voltados ao treinamento de funcionários, manutenção dos padrões de segurança, higiene além da qualidade dos produtos entregues aos clientes.

\section{REFERÊNCIAS}

Abrasel São Paulo. (2017). Retrieved May 26, 2017, from http://www.sp.abrasel.com.br/

Angnes, D. L., Mello Moyano, C. A., \& Lengler, J. F. B. (2015). Avaliação da Satisfação do Cliente em Serviços de Restaurantes com Aplicação do ACSI. Revista Brasileira de Pesquisa Em Turismo, 9(1), 174. https://doi.org/10.7784/rbtur.v9i1.725

Angnes, D. L., \& Moyano, C. A. M. (2013). Atributos de escolha em serviços de restaurantes: Um estudo exploratório. Revista Brasileira de Pesquisa Em Turismo, 7(2), 317-336. https://doi.org/10.7784/rbtur.v7i2.607
Arsham, H. (1988). Kuiper's P-value as a measuring tool and decision procedure for the goodness-of-fit test. Journal of Applied Statistics, 15(2), 131-135. https://doi.org/10.1080/02664768800000020

Aureliano-Silva, L., Oliveira, P. S. G. de, \& Alves, C. A. (2017). A relação entre a felicidade e o desejo por hospitalidade mediada pela autoimagem do turista e a imagem do seu destino. Revista Brasileira de Pesquisa Em Turismo, 11(3), 436. https://doi.org/10.7784/rbtur.v11i3.1324

Blain, M., \& Lashley, C. (2014). Hospitableness: the new service metaphor? Developing an instrument for measuring hosting. Research in Hospitality Management, 4(1\&2), 1-8. https://doi.org/10.1080/22243534.2014.11828307

Brotherton, B., \& Wood, R. (2004). Hospitalidade e administração da hospitalidade. In Em busca da hospitalidade: perspectivas de um mundo globalizado. São Paulo: Manole.

Camargo, L. O. de L. (2004). Hospitalidade. São Paulo: Aleph.

Camargo, L. O. de L. (2015). Os interstícios da hospitalidade. Revista Hospitalidade, XII(Número Especial), 42-69.

Carvalho, L. G. A., Bastos, S. R., \& Gimenes-Minasse, M. H. S. G. (2016). Commensality in Nuclear Family of São Paulo: 1950 to 2000. Revista Rosa Dos Ventos Turismo E Hospitalidade, 9(1), 18-31. https://doi.org/10.18226/21789061.v9i1p018

Cohen, J. (1977). Statistical power analysis for the behavioral sciences. New York: Academic Press.

Creswell, J. W. (2013). Research design: Qualitative, quantitative, and mixed methods approaches. Sage publications.

Dhar, R. L. (2015a). Service quality and the training of employees: The mediating role of organizational commitment. Tourism Management, 46, 419-430.

Dhar, R. L. (2015b). The effects of high performance human resource practices on service innovative behaviour. International Journal of Hospitality Management, 51(October 2015), 67-75. https://doi.org/10.1016/j.ijhm.2015.09.002

Erdfelder, E., Faul, F., \& Buchner, A. (1996). GPOWER: 
A general power analysis program. Behavior Research Methods, Instruments, \& Computers, 28(1), 1-11. https://doi.org/10.3758/BF03203630

Farias, S. A. de. (2005). Atmosfera de Loja On-line: o Impacto do Ambiente Virtual na Satisfação do Consumidor. XXIX EnANPAD - Encontro Da ANPAD, 16.

Farias, S. A. de, \& Santos, R. da C. (2000). Modelagem de equações estruturais e satisfação do consumidor: uma investigação teórica e prática. Revista de Administração Contemporânea, 4(3), 107-132. https://doi.org/10.1590/S1415-65552000000300007

Faul, F., Erdfelder, E., Buchner, A., \& Lang, A.-G. (2009). Statistical power analyses using G*Power 3.1: Tests for correlation and regression analyses. Behavior Research Methods, 41(4), 1149-1160. https://doi.org/10.3758/BRM.41.4.1149

Fávero, L. P., Belfiore, P., Silva, F. L. da, \& Chan, B. L. (2009). Análise de dados: modelagem multivariada para tomada de decisões.

Fornell, C., \& Larcker, D. F. (1981). Structural equation models with unobservable variables and measurement error: Algebra and statistics. Journal of Marketing Research, 382-388.

Grönroos, C. (1984). A Service Quality Model and its Marketing Implications. European Journal of Marketing, 18(4), 36-44. https://doi.org/10.1108/EUM0000000004784

Guiry, M., Scott, J. J., \& Vequist, D. G. (2013). Experienced and potential medical tourists' service quality expectations. International Journal of Health Care Quality Assurance, 26(5), 433-446. https://doi.org/10.1108/IJHCQA-05-2011-0034

Hair, J. F., Black, W. C., Babin, B. J., Anderson, R. E., \& Tatham, R. L. (2010). Multivariate data analysis. Pearson College Division.

Hair, J. F., Ringle, C. M., \& Sarstedt, M. (2011). PLSSEM: Indeed a Silver Bullet. The Journal of Marketing Theory and Practice, 19(2), 139-152. https://doi.org/10.2753/MTP1069-6679190202

Hwang, J., \& Ok, C. (2013). The antecedents and consequence of consumer attitudes toward restaurant brands: A comparative study between casual and fine dining restaurants. International Journal of Hospitality Management, 32(1), 121-131. https://doi.org/10.1016/j.ijhm.2012.05.002
Johnson, M. D., Gustafsson, A., Andreassen, T. W., Lervik, L., \& Cha, J. (2001). The evolution and future of national customer satisfaction index models. Journal of Economic Psychology, 22(2), 217-245. https://doi.org/10.1016/S0167-4870(01)00030-7

Jung, H. S., \& Yoon, H. H. (2013). Do employees' satisfied customers respond with an satisfactory relationship? The effects of employees' satisfaction on customers' satisfaction and loyalty in a family restaurant. International Journal of Hospitality Management, 34(1), 1-8. https://doi.org/10.1016/j.ijhm.2013.02.003

Kim, D., \& Jang, S. (2014). Motivational drivers for status consumption: A study of Generation Y consumers. International Journal of Hospitality Management, 38, 39-47. https://doi.org/10.1016/j.ijhm.2013.12.003

Kim, J. H., \& Jang, S. (Shawn). (2014). The fading affect bias: Examining changes in affect and behavioral intentions in restaurant service failures and recoveries. International Journal of Hospitality Management, 40, 109-119. https://doi.org/10.1016/j.ijhm.2014.03.011

Kim, M. G., Lee, C. H., \& Mattila, A. S. (2014). Determinants of Customer Complaint Behavior in a Restaurant Context: The Role of Culture, Price Level, and Customer Loyalty. Journal of Hospitality Marketing \& Management, 23(8), 885-906. https://doi.org/10.1080/19368623.2014.896762

Krause, R. W., \& Bahls, Á. A. D. S. M. (2016). Serviços clássicos na restauração comercial: proposta de padronização e esclarecimentos para futuras pesquisas. Revista Brasileira de Pesquisa Em Turismo, 10(3), 550-573. https://doi.org/10.7784/rbtur.v10i3.1186

Lee, C.-C., Chiang, C., \& Chen, C.-T. (2012). An evaluation model of e-service quality by applying hierarchical fuzzy TOPSIS method. International Journal of Electronic Business Management, 10(1), 38.

Liu, J. T. (2016). Research on Taiwan Theme Parks' Experience Marketing Strategy and Revisit Willingness, Purchase Willingness and Recommendation Willingness. The International Journal Of Organizational Innovation Num, 9(July 2016), 35-53.

Lockwood, A., \& Jones, P. (2004). Administração das 
operações de hospitalidade. Em Busca Da Hospitalidade: Perspectivas de Um Mundo Globalizado. São Paulo: Manole.

Lovelock, C., \& Wirtz, J. (2006). Marketing de Serviços: uma orientação aplicada. Porto Alegre: Prentice Hall.

Lugosi, P., Lambie-Mumford, H., \& Tonner, A. (2014). Food, drink and hospitality: Space, materiality, practice. Hospitality \& Society.

Maghnati, F., Ling, K. C., \& Nasermoadeli, A. (2012). Exploring the Relationship between Experiential Marketing and Experiential Value in the Smartphone Industry. International Business Research, 5(11), 169. https://doi.org/10.5539/ibr.v5n11p169

McPhail, R., Patiar, A., Herington, C., Creed, P., \& Davidson, M. (2015). Development and initial validation of a hospitality employees' job satisfaction index. International Journal of Contemporary Hospitality Management, 27(8), 1814-1838. https://doi.org/10.1108/IJCHM-03-2014-0132

Namkung, Y., \& Jang, S. (Shawn). (2017). Are Consumers Willing to Pay more for Green Practices at Restaurants? Journal of Hospitality \& Tourism Research, 41(3), 329-356. https://doi.org/10.1177/1096348014525632

Oliveira, A. S. de;, Silva, D. da;, Rodrigues, G. V., \& Borges, R. C. (2014). A Qualidade Percebida e a Satisfação como Antecedentes Diretos da Lealdade: Um Estudo em Processo de Compra de Baixo Envolvimento no Varejo. In XVII SemeAd - Seminários em Administração (pp. 1-16).

Parasuraman, A., Zeithaml, V. A., \& Berry, L. L. (1988). SERVQUAL: A multiple-item scale for measuring consumer perceptions of service quality. Journal of Retailing, 64(1), 12.

Pine, B. J., \& Gilmore, J. H. (1999). The experience economy: work is theatre \& every business a stage. Harvard Business Press.

Ringle, C. M., Wende, S., \& Becker, J.-M. (2015). SmartPLS

https://doi.org/http://www.smartpls.com

Ryu, K., \& Lee, J.-S. (2017). Examination of Restaurant Quality, Relationship Benefits, and Customer Reciprocity From the Perspective of Relationship Marketing Investments. Journal of Hospitality \&
Tourism Research, 41(1), 66-92. https://doi.org/10.1177/1096348013515919

Schmitt, B. (1999). Experiential Marketing. Journal of Marketing Management, 15(1-3), 53-67. https://doi.org/10.1362/026725799784870496

Schmitt, B. (2010). Experience Marketing: Concepts, Frameworks and Consumer Insights. Foundations and Trends ${ }^{\circledR}$ in Marketing, 5(2), 55-112. https://doi.org/10.1561/1700000027

Shing, G. L., Koh, C., \& Nathan, R. J. (2012). Service Quality Dimensions and Tourist Satisfaction Towards Melaka Hotels. International Journal of Economics and Management Engineering, 2(1), 26-32.

Srinivasan, S. S., Anderson, R., \& Ponnavolu, K. (2002). Customer loyalty in e-commerce: an exploration of its antecedents and consequences. Journal of Retailing, 78(1), 41-50. https://doi.org/10.1016/S00224359(01)00065-3

Stefanini, C. J., Souza, R. B. M., \& Yamashita, A. P. N. G. (2012). Turismo de negócios: um estudo sobre a percepção de valor dos serviços hoteleiros na ótica do turista de negócios. Revista Turismo Visão E Ação, 14(3), 349-365. https://doi.org/10.14210/rtva.v14n3.p349-365

Tarţa, C. P. (2013). The perception of young romanians on experiential marketing. Management \& Marketing Journal, 11(2).

Telfer, E. (2004). A filosofia da qualidade da hospitalidade. In Lashley, C.; Morrisson, A. Em busca da hospitalidade: perspectivas para um mundo globalizado. Manole, Barueri.

Teng, C. C., \& Chang, J. H. (2013). Mechanism of customer value in restaurant consumption: Employee hospitality and entertainment cues as boundary conditions. International Journal of Hospitality Management, 32(1), 169-178. https://doi.org/10.1016/i.ijhm.2012.05.008

Tynan, C., \& McKechnie, S. (2009). Experience marketing: a review and reassessment. Journal of Marketing Management, 25(5-6), 501-517. https://doi.org/10.1362/026725709X461821

Wada, E. K., \& Camargo, L. O. de L. (2006). Os desafios da hotelaria. GV-executivo (Vol. 5). Fundação Getúlio Vargas, Escola de Administração de Empresas de São 
Paulo.

Walls, A. R. (2013). A cross-sectional examination of hotel consumer experience and relative effects on consumer values. International Journal of Hospitality Management, 32(1), 179-192. https://doi.org/10.1016/j.ijhm.2012.04.009

Warech, M., \& Tracey, J. B. (2004). Evaluating the impact of human resources: Identifying what matters. Cornell Hotel and Restaurant Administration Quarterly, 45(4), 376-387. https://doi.org/10.1177/0010880404266247

Werdini, M. M., Rejowski, M., \& Stefanini, C. J. C. J. (2014). Formação superior em gastronomia na cidade de São Paulo: expectativas e satisfação de alunos de uma instituição privada. CULTUR: Revista de Cultura $E$ Turismo, 8(1), 35-58.

Westbrook, R. A., \& Oliver, R. (1991). The Dimensionality of Consumption Emotion Pattems and Consumer Satisfaction. Journal of Consumer Research, 18(1), 84-91. https://doi.org/10.1086/209243

\section{Dados dos autores}

\section{Cláudio José Stefanini}

Professor do Programa de Pós-Graduação em Hospitalidade (Mestrado e Doutorado) - Universidade Anhembi Morumbi (UAM), São Paulo, SP, Brasil. Email: cjstefanini@gmail.com

\section{Carlos Alberto Alves}

Professor do Programa de Pós-Graduação em Hospitalidade (Mestrado e Doutorado) e do Mestrado Profissional Gestão em Alimentos e Bebidas - Universidade Anhembi Morumbi (UAM), São Paulo, SP, Brasil. Email: calves761@gmail.com

\section{Roseane Barcellos Marques}

Professora do Programa de Pós-Graduação em Hospitalidade (Mestrado e Doutorado) - Universidade Anhembi Morumbi (UAM), São Paulo, SP, Brasil. Email: roseanebmarques@yahoo.com.br 